Research Article

\title{
Pharmacological Basis for Use of Armillaria mellea Polysaccharides in Alzheimer's Disease: Antiapoptosis and Antioxidation
}

\author{
Shengshu An, ${ }^{1}$ Wenqian Lu, ${ }^{1}$ Yongfeng Zhang, ${ }^{1}$ Qingxia Yuan, ${ }^{1}$ and Di Wang ${ }^{1,2}$ \\ ${ }^{1}$ School of Life Sciences, Jilin University, Changchun 130012, China \\ ${ }^{2}$ Zhuhai College, Jilin University, Zhuhai 519041, China
}

Correspondence should be addressed to Di Wang; jluwangdi@outlook.com

Received 23 March 2017; Revised 19 July 2017; Accepted 27 July 2017; Published 10 September 2017

Academic Editor: Anna M. Giudetti

Copyright (C) 2017 Shengshu An et al. This is an open access article distributed under the Creative Commons Attribution License, which permits unrestricted use, distribution, and reproduction in any medium, provided the original work is properly cited.

\begin{abstract}
Armillaria mellea, an edible fungus, exhibits various pharmacological activities, including antioxidant and antiapoptotic properties. However, the effects of A. mellea on Alzheimer's disease (AD) have not been systemically reported. The present study aimed to explore the protective effects of mycelium polysaccharides (AMPS) obtained from A. mellea, especially AMPSc via $70 \%$ ethanol precipitation in a L-glutamic acid- (L-Glu-) induced HT22 cell apoptosis model and an $\mathrm{AlCl}_{3}$ plus D-galactose- (D-gal-) induced AD mouse model. AMPSc significantly enhanced cell viability, suppressed nuclear apoptosis, inhibited intracellular reactive oxygen species accumulation, prevented caspase- 3 activation, and restored mitochondrial membrane potential (MMP). In $\mathrm{AD}$ mice, AMPSc enhanced horizontal movements in an autonomic activity test, improved endurance times in a rotarod test, and decreased escape latency time in a water maze test. Furthermore, AMPSc reduced the apoptosis rate, amyloid beta (A $\beta$ ) deposition, oxidative damage, and p-Tau aggregations in the $\mathrm{AD}$ mouse hippocampus. The central cholinergic system functions in $\mathrm{AD}$ mice improved after a 4-week course of AMPSc administration, as indicated by enhanced acetylcholine (Ach) and choline acetyltransferase (ChAT) concentrations, and reduced acetylcholine esterase (AchE) levels in serum and hypothalamus. Our findings provide experimental evidence suggesting A. mellea as a neuroprotective candidate for treating or preventing neurodegenerative diseases.
\end{abstract}

\section{Introduction}

Devastating neurodegenerative disorders, such as Alzheimer's disease $(\mathrm{AD})$, are caused by neuronal loss and synapse degeneration. These disorders are clinically characterized by learning and memory decline, as well as cognitive deficits, and no cure is currently available [1]. The neuronal losses observed in neurodegenerative diseases are attributable to the oxidative death of these oxidative stress-sensitive cells [2]. Oxidative stress promotes neurotoxicity by increasing amyloid beta $(\mathrm{A} \beta)$ aggregation concomitantly with inflammatory events such as reactive oxygen species (ROS) production [3]. Additionally, excess extracellular glutamate levels have been found to correlate with the development of neurodegenerative disorders by triggering oxidative glutamate damage, preventing the intracellular antioxidant synthesis, and ultimately leading to ROS accumulation [4]. The overproduction of ROS and $A \beta$ causes a feedback loop that results in synaptic dysfunction, as well as mitochondria-mediated apoptosis [5]. Therefore, antioxidant therapies are being considered as new options for protecting neurons from the oxidative damage associated with $\mathrm{AD}$. These antioxidants not only can scavenge free radicals but may also reduce damage due to oxidative stress and thus maintain the cellular redox balance [6].

Several types of fungus are currently used as functional foods. In addition, many exhibit pharmacological activities with few side effects and are used as medicinal agents. Encouragingly, many fungal species have been reported to display neuroprotective properties in the context of 


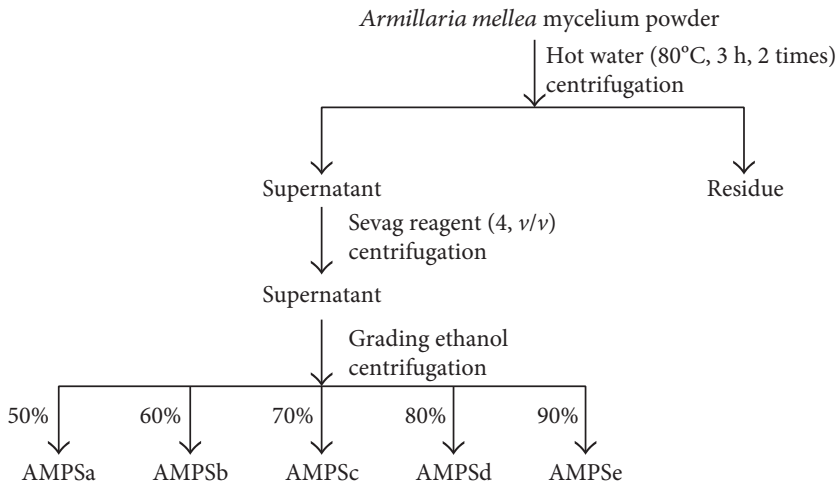

(a)

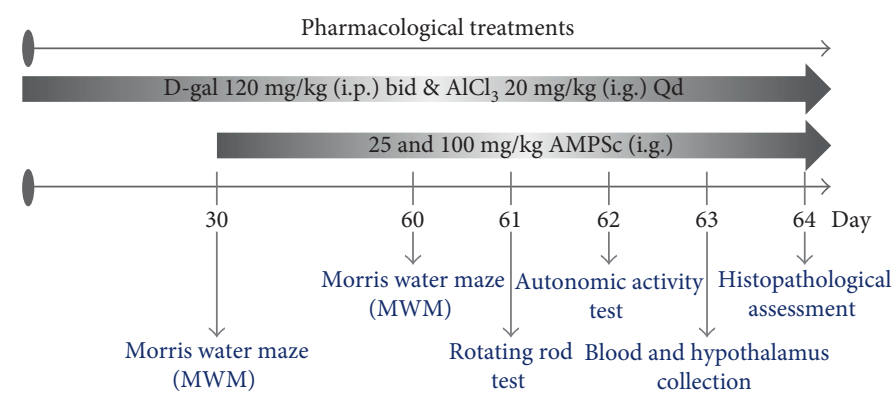

(b)

FIgURE 1: (a) The preparation of polysaccharides isolated from A. mellea mycelium obtained via submerged fermentation. (b) The process of $\mathrm{AlCl}_{3}$ combined with D-gal-induced Alzheimer's disease mouse model establishment and drug administration.

neurodegenerative diseases [7]. Our group found that a polysaccharide isolated from Sparassis crispa protected PC12 cells against L-glutamic acid- (L-Glu-) induced apoptosis via the mitochondrial apoptotic pathway [8]. Furthermore, aqueous extracts of Hericium erinaceus yielded therapeutic effects that were attributed to both mitochondria-mediated apoptosis and neurotransmitter modulation in apoptotic cells and in an $\mathrm{AlCl}_{3}$ plus D-galactose- (D-gal-) induced mouse model of AD [9]. Armillaria mellea, an edible and medicinal fungus, has been used for hundreds of years in East Asia. Polysaccharides isolated from A. mellea have been reported to exhibit antioxidant activities by superoxide radical scavenging [10] and significant antitumor activities via the mitochondrial apoptotic pathway and caspase cascade activation [11]. All previous data have indicated that $A$. mellea may exert protective effects against neurodegenerative diseases, especially AD.

The neurotoxin-induced mouse hippocampal neuronal cell (i.e., HT22 cell) apoptosis model is a well-recognized in vitro model for screening the neuroprotective effects of various agents [12]. Additionally, an aging model induced by $\mathrm{D}$-gal is used in animal studies. This model involves the blocking of natural physiological features of aging and exhibits cellular $\mathrm{AD}$ phenomena, including a wide range of astrocytic and neuronal vacuolization, neuronal degeneration or death, and $\mathrm{A} \beta$ production and deposition, followed by cerebral cortex atrophy and cognitive and memory dysfunction [13]. The use of a combination of $\mathrm{AlCl}_{3}$ and $\mathrm{D}$-gal in a mouse model induces $\mathrm{AD}$-like behavior and more readily generates pathological alterations than either $\mathrm{AlCl}_{3}$ - or D-gal-only treatment [14].

In the present study, we used L-Glu-induced HT22 apoptotic cells and $\mathrm{D}$-gal plus $\mathrm{AlCl}_{3}$-induced $\mathrm{AD}$ mice to investigate the neuroprotective effects of A. mellea mycelium polysaccharides (AMPS). We found that in HT22 cells, AMPS improved cell viability, restored mitochondrial membrane potential (MMP), and reduced cell apoptosis and excess caspase- 3 activity. Moreover, AMPS treatment regulated the behavior and physiological and biochemical indexes of $\mathrm{AD}$ mice. Taken together, our data suggest the usefulness of $A$. mellea as a therapeutic agent or functional food for the treatment of $\mathrm{AD}$.
TABLE 1: Effect of different ratios of ethanol on the polysaccharides yield from $A$. mellea mycelium.

\begin{tabular}{lcc}
\hline Ethanol concentration & Name & Yield (\%) \\
\hline $50 \%$ & AMPSa & 0.93 \\
$60 \%$ & AMPSb & 1.30 \\
$70 \%$ & AMPSc & 1.93 \\
$80 \%$ & AMPSd & 1.60 \\
$90 \%$ & AMPSe & 1.00 \\
\hline
\end{tabular}

\section{Materials and Methods}

2.1. Preparation of A. mellea Polysaccharides. A. mellea (CICC 14066; China Center of Industrial Culture Collection, Beijing, China) mycelium was obtained through submerged fermentation with the medium consisted of $20 \mathrm{~g} / \mathrm{L}$ of sucrose, $10 \mathrm{~g} / \mathrm{L}$ of glucose, $10 \mathrm{~g} / \mathrm{L}$ yeast extract powder, $10 \mathrm{~g} / \mathrm{L}$ of peptone, $1.5 \mathrm{~g} / \mathrm{L}$ of $\mathrm{KH}_{2} \mathrm{PO}_{4}, 0.75 \mathrm{~g} / \mathrm{L}$ of $\mathrm{MgSO}_{4}$, and $0.01 \mathrm{~g} / \mathrm{L}$ of vitamin $\mathrm{B} 1$. A. mellea was extracted by hot water at $80^{\circ} \mathrm{C}$ for $3 \mathrm{~h}$ twice, removed proteins using Sevag reagent (n-butanol and chloroform in 1:4 ratio), and then collected after precipitation using $50 \%, 60 \%, 70 \%, 80 \%$, and $90 \%$ ethanol at $4^{\circ} \mathrm{C}$ overnight and named AMPSa-e (Figure 1(a)). The yield of polysaccharides within A. mellea mycelium was shown in Table 1.

2.2. Cell Culture. The mouse hippocampal neuronal cell line (HT22; BNCC; 337709) was cultured in Dulbecco's modified Eagle's medium (DMEM; Invitrogen, USA) supplemented with $10 \%$ fetal bovine serum (FBS, Invitrogen, USA), $100 \mu \mathrm{g} / \mathrm{mL}$ streptomycin, and $100 \mathrm{units} / \mathrm{mL}$ penicillin (Invitrogen, USA) in a 5\% CO2 and $95 \%$ air incubator supplying a humidified atmosphere at $37^{\circ} \mathrm{C}$. Before treatment, HT22 cells were differentiated in Neurobasal medium (Invitrogen) containing $2 \mathrm{mmol} / \mathrm{L}$ glutamine and $1 \times \mathrm{N}_{2}$ supplement (Invitrogen) for 24 hours [15].

2.3. Cell Viability Assay. HT22 cells were pretreated with AMPSa-e at a dose of $40 \mu \mathrm{g} / \mathrm{mL}$ or AMPSc at doses of $10,20,40$, and $80 \mu \mathrm{g} / \mathrm{mL}$ for $3 \mathrm{~h}$ and then incubated with $25 \mathrm{mM}$ of L-GLu for $24 \mathrm{~h}$. 3-(4,5-Dimethyl-2-thiazolyl)- 
2,5-diphenyl-2H-tetrazolium bromide assay (MTT, SigmaAldrich, USA) was applied for cell viability assessment similarly as previous research [8].

2.4. Cell Apoptosis Assay. HT22 cells were pretreated with AMPSc at doses of 40 and $80 \mu \mathrm{g} / \mathrm{mL}$ for $3 \mathrm{~h}$ and then incubated with $25 \mathrm{mM}$ of L-Glu for another $24 \mathrm{~h}$. Cells were then incubated with propidium iodide (PI) and annexin $\mathrm{V}$ (AV) for $20 \mathrm{~min}$ at room temperature in darkness. The intensity of fluorescence was measured utilizing Muse ${ }^{\mathrm{TM}}$ Cell Analyzer from Millipore (Billerica, MA) following manufacturer's instructions.

2.5. MMP Assay. Cells were pretreated with AMPSc (40 and $80 \mu \mathrm{g} / \mathrm{mL}$ ) for $3 \mathrm{~h}$ and then exposed to $25 \mathrm{mM}$ of L-Glu for another $12 \mathrm{~h}$ and then incubated with JC-1 $\left(5,5^{\prime}, 6,6^{\prime}\right.$-tetrachloro-1,1'3,3'tetraethylbenzimidazol-ylcarbocyanine iodide) at $37^{\circ} \mathrm{C}$ for $20 \mathrm{~min}$ in darkness. The ratio of green/red fluorescence analyzed using Muse Cell Analyzer (Millipore; USA) indicated the value of mitochondrial membrane potential.

2.6. Intracellular ROS Generation Assessment. HT22 cells were pretreated with AMPSc (40 and $80 \mu \mathrm{g} / \mathrm{mL}$ ) for $3 \mathrm{~h}$ and then exposed to $25 \mathrm{mM}$ of L-Glu for another $12 \mathrm{~h}$. Treated cells were incubated with $10 \mu \mathrm{mol} / \mathrm{L}$ of $2^{\prime}, 7^{\prime}$-dichlorofluorescein diacetate (DCFH-DA) at $37^{\circ} \mathrm{C}$ for 20 minutes. Green fluorescence intensity detected with a fluorescent microscope (40x; CCD camera, IX73, Olympus) represented the level of intracellular ROS.

2.7. Assessment of Caspase Activities. HT22 cells were pretreated with AMPSc (40 and $80 \mu \mathrm{g} / \mathrm{mL}$ ) for $3 \mathrm{~h}$ and then exposed to $25 \mathrm{mM}$ of L-Glu for another $24 \mathrm{~h}$. The activities of caspase-3 were analyzed via commercial kits (Nanjing Jiancheng Bioengineering Institute, Nanjing, China).

2.8. Experiments Applied on Alzheimer's Disease Mouse Model. The experiments were carried out under the approval of Institution Animal Ethics Committee of Jilin University. $50 \mathrm{Balb} / \mathrm{c}$ male mice (20-22 g; 10 weeks) were housed in cages in an air-conditioned room under temperature $\left(23 \pm 1^{\circ} \mathrm{C}\right)$ and humidity (40-60\%) with sufficient water and food and randomly divided into five groups $(n=10) .30$ mice were subcutaneously injected with $120 \mathrm{mg} / \mathrm{kg}$ of D-gal and orally treated with $20 \mathrm{mg} / \mathrm{kg}$ of $\mathrm{AlCl}_{3}$ once a day for 8 weeks. Starting from the fifth week, mice were intragastrically treated with normal saline (model group) and AMPSc at doses of 25 and $100 \mathrm{mg} / \mathrm{kg} /$ day for four weeks. 10 mice serving as control group were treated with normal saline for 8 weeks. Another 10 mice were treated with normal saline for 4 weeks, following with $100 \mathrm{mg} / \mathrm{kg}$ of AMPSc administration for another 4 weeks (Figure 1(b)).

At the end of behavioral tests as follows, blood was collected from the rats' tails under anesthesia with $10 \%$ chloral hydrate, and the brains were removed and homogenized $(1: 9 w / v)$ in $\mathrm{NaCl}$ buffer. The whole hemisphere was immersed in $4 \%$ formaldehyde for pathologic analysis.

\subsection{Behavioral Tests}

2.9.1. Morris Water Maze Test. Memory ability and spatial learning were analyzed by Morris water maze (MT-200, Chengdu, China). After 5-day training, on the 60th day, mice were put into a circular pool filled with opacified water containing titanium dioxide $\left(23 \pm 2^{\circ} \mathrm{C}, 10 \mathrm{~cm}\right.$ in depth). The escape latency of mice to find the platform was recorded within $120 \mathrm{~s}$.

2.9.2. Fatigue Rotarod Test. On the 61st day, after 3 times training, mice were placed on the turning device (ZB-200, Chengdu Techman Software Co. Ltd., Chengdu, China) with $15 \mathrm{rpm}$ speed, and the time when mice under induced muscle fatigue fell off was recorded.

2.9.3. Autonomic Activity Test. On the 62nd day, mice were placed in the chamber covered with the light-blocking plate to detect their autonomic activities. The number of mouse activities including the horizontal movements and the vertical movements was recorded for $5 \mathrm{~min}$.

2.10. Determination of the Levels of Ach, AchE, and ChAT in Serum and Hypothalamus. The levels of acetylcholine (Ach), acetylcholine esterase (AchE), and choline acetyltransferase (ChAT) in serum and hypothalamus were measured by enzyme-linked immunosorbent assay (ELISA) according to the procedures provided by the related assay kits (Nanjing Jiancheng Bioengineering Institute, Nanjing, China).

2.11. Determination of Oxidation Status in Serum or Hypothalamus. The levels of superoxide dismutase (SOD), glutathione peroxidase (GSH-Px), and ROS in serum and/ or hypothalamus were detected by ELISA kit according to related procedures (Nanjing Jiancheng Bioengineering Institute, Nanjing, China).

2.12. TUNEL Assay. Apoptosis in the hippocampus was detected using the terminal deoxynucleotidyl transferasemediated dUTP nick end labeling (TUNEL). After deparaffinization, hippocampus tissue sections were washed twice in phosphate-buffered saline (PBS) for 5 minutes and completely covered by the permeabilization reagent (Proteinase $\mathrm{K}$ ) for $15 \mathrm{~min}$ at room temperature. After washing with PBS, sections were incubated with $50 \mu \mathrm{L}$ of the prepared $\mathrm{TdT}$ reaction mixture at $37^{\circ} \mathrm{C}$ for $60 \mathrm{~min}$ in the dark. The reactions were subsequently terminated, and the tissue sections were analyzed under a Nikon Eclipse TE 2000-S fluorescence microscope (20x; CCD camera, IX73, Olympus).

2.13. Determination of Levels of $A \beta$ in Serum and Hippocampus. The levels of A $\beta 1-42$ in serum were detected by ELISA kit according to related procedures (Nanjing Jiancheng Bioengineering Institute, Nanjing, China).

Brain coronal sections were deparaffinized, placed in thioflavin-S solution for $5 \mathrm{~min}$, and then differentiated in $70 \%$ fresh alcohol for $10 \mathrm{~min}$. After washing, images were captured using a confocal microscope (40x; CCD camera, IX73, Olympus). 
2.14. Immunohistochemistry. The protein expressions of $\mathrm{A} \beta 1$ 40, phospho- (p-) Tau (ser404), and 4-hydroxynonenal (4-HNE) in the hippocampus of mice were detected via immunohistochemistry to visualize $\mathrm{A} \beta$ deposition, tau aggregations, and oxidative stress-associated damage. The paraffin sections were deparaffinized in xylene and rehydrated in different graded alcohol. Then, sections were heated in antigen repair solution (citrate buffer) in a microwave for $20 \mathrm{~min}$ to retrieve antigens. After extensive washing with PBS for $5 \mathrm{~min}$, sections were incubated with $3 \%$ hydrogen peroxide for $10 \mathrm{~min}$ at room temperature to block endogenous peroxidase followed by blocking with $2 \%$ goat serum dissolved in PBS. The slides were incubated with polyclonal anti-A $\beta 1-40 \quad(1: 200$, Bioss bs0877R); anti-p-Tau (ser404) (1:200, Bioss bs-2392R); and anti-4-HNE (1:800, Abcam: ab46545) antibodies individually overnight at $4^{\circ} \mathrm{C}$. Subsequently, slides were washed with PBS and incubated with secondary antibody conjugated horseradish peroxidase (HRP) at room temperature for $1 \mathrm{~h}$. And then, the sections were washed in PBS and visualized with DAB (3,3'-diaminobenzidine) (Solarbio, Beijing, China) followed by incubating with Mayer's hematoxylin for $3 \mathrm{~min}$. Finally, the sections were dehydrated with dilutions of ethanol and xylene and digitized using an Olympus IX73 microscope (Olympus, Tokyo, Japan).

2.15. Statistical Analysis. Data were expressed as mean \pm S.E.M. A one-way analysis of variance (ANOVA) was used to detect statistical significance followed by post hoc multiple comparisons (Dunn's test). Statistical significance was accepted for $P<0.05$.

\section{Results}

3.1. AMPS Improved Cell Viability and Apoptosis and Reduced Caspase-3 Activity. Compared with L-Glu-treated cells, cells pretreated with $40 \mu \mathrm{g} / \mathrm{mL}$ of AMPSb and AMPSc for $3 \mathrm{~h}$ improved HT22 cell viability by $10 \%$ and $11 \%$, respectively $(P<0.05$; Figure $2(\mathrm{a}))$, whereas treatment with AMPSa, d, and e had no effect. Additionally, pretreatment with 40 or $80 \mu \mathrm{g} / \mathrm{mL}$ of AMPSc for $3 \mathrm{~h}$ before a $24 \mathrm{~h}$ incubation with $25 \mathrm{mM}$ of L-Glu improved HT22 cell viability by $6.9 \%$ and $13.7 \%$, respectively $(P<0.05$; Figure $2(\mathrm{~b}))$. AV-PI staining revealed that whereas exposure to $25 \mathrm{mM} \mathrm{L}-\mathrm{Glu}$ led to an apoptosis rate of $25 \%$ in HT22 cells, a $3 \mathrm{~h}$ preincubation with AMPSc led to a reduction in apoptosis of $>14 \%$ (Figure 2(c)). When compared to L-Glu-damaged HT22 cells, a $3 \mathrm{~h}$ AMPSc pretreatment reduced caspase- 3 activity by $>24 \%$ during a $24 \mathrm{~h}$ incubation (Figure $2(\mathrm{~d})$ ).

3.2. AMPSc Restored the Dissipation of MMP and Reduced ROS Accumulation. Altered mitochondrial apoptosis, which is characterized by disruption of the MMP, is a common feature of cell apoptosis [8]. Compared with L-Glu-damaged HT22 cells, AMPSc improved MMP depolarization by nearly $10 \%$ after a $12 \mathrm{~h}$ incubation (Figure 3(a)). Furthermore, a 3-h AMPSc pretreatment strongly suppressed L-Glu-induced
ROS accumulation, as indicated by reduced green fluorescence (Figure 3(b)).

3.3. AMPSc Affected the Behavior of AD Mice. We next subjected $\mathrm{D}$-gal plus $\mathrm{AlCl}_{3}$-induced $\mathrm{AD}$ model mice for behavioral testing to further confirm the beneficial activities of AMPSc against AD. In an autonomic activity test, AMPSc enhanced the horizontal movements of $\mathrm{AD}$ mice relative to controls $(P<0.05$; Figure $4(\mathrm{a}))$, but failed to influence vertical movements $(P>0.05$; Figure $4(b))$. In a fatigue rotarod test, AMPSc enhanced the endurance times of $\mathrm{AD}$ mice by $>25 \%(P<0.01$; Figure $4(\mathrm{c}))$ but had no significant effects on control mice (Figure $4(\mathrm{c})$ ).

The water maze test is commonly used to evaluate learning and memory in animals [16]. Here, we applied this test to evaluate the effects of AMPS on the cognitive abilities of $\mathrm{AD}$ mice. We initially observed a $>15 \%$ enhancement in the escape latency times of $\mathrm{AD}$ mice $(P<0.01$; Figure $4(\mathrm{~d}))$. A 4 -week course of AMPSc administration led to a nearly $20 \%$ decrease in the escape latency times $(P<0.05$; Figure 4(d)). AMPSc failed to influence the escape latency times of control mice $(P>0.05$; Figure $4(\mathrm{~d}))$.

TUNEL staining was used to analyze the apoptotic statuses of hippocampal neurons. In both control and AMPSctreated mice, we observed few TUNEL-positive cells, suggesting that a minority of neurons were apoptotic. Larger amounts of TUNEL-positive apoptotic neurons were noted in AD mice, whereas a 4-week course of AMPSc administration strongly reduced apoptosis in this population, as demonstrated by the reduction in green fluorescence intensity (Figure 4(e)).

3.4. AMPSc Regulated Ach, AchE, and ChAT Concentrations in Serum and Hypothalamus. We noted significant reductions in the serum and hypothalamic Ach and ChAT concentrations, which were accompanied by increased AchE concentrations, in $\mathrm{AlCl}_{3}$ and $\mathrm{D}$-gal-induced $\mathrm{AD}$ mice relative to control mice $(P<0.05$; Figure 5$)$, suggesting disruption of the central cholinergic function. Compared to $\mathrm{AD}$ mice, AMPSc increased both the Ach and ChAT levels and reduced the AchE levels in the serum and hypothalamus in a dosedependent manner $(P<0.05$; Figure 5$)$.

3.5. AMPSc Regulated Oxidative Status in the Serum and Hypothalamus. Oxidative stress is the basis for an important hypothesis regarding the pathophysiology of neurodegenerative disorders. Compared with control mice, AMPSc alone significantly enhanced the serum and/or hypothalamic levels of SOD and GSH-Px and reduced the levels of ROS in $\mathrm{AD}$ mice $(P<0.05$; Table 2). Compared with $\mathrm{AD}$ mice, a 4-week course of AMPSc administration yielded in $>50 \%$ and $20 \%$ increases in SOD and GSH-Px activities, resp., and a $>45 \%$ reduction in ROS levels in the serum and/or hypothalamus $(P<0.01$; Table 2$)$.

3.6. AMPSc Regulated $A \beta$ Levels in the Serum and Hippocampus. $\mathrm{A} \beta$, which exhibits strong aggregating properties, is considered the core component of amyloid plaques. Compared with control mice, we observed no significant changes in the serum $A \beta 1-42$ levels in $A D$ mice, whereas a 4 -week course of AMPSc led to a $>20 \%$ increase in serum 


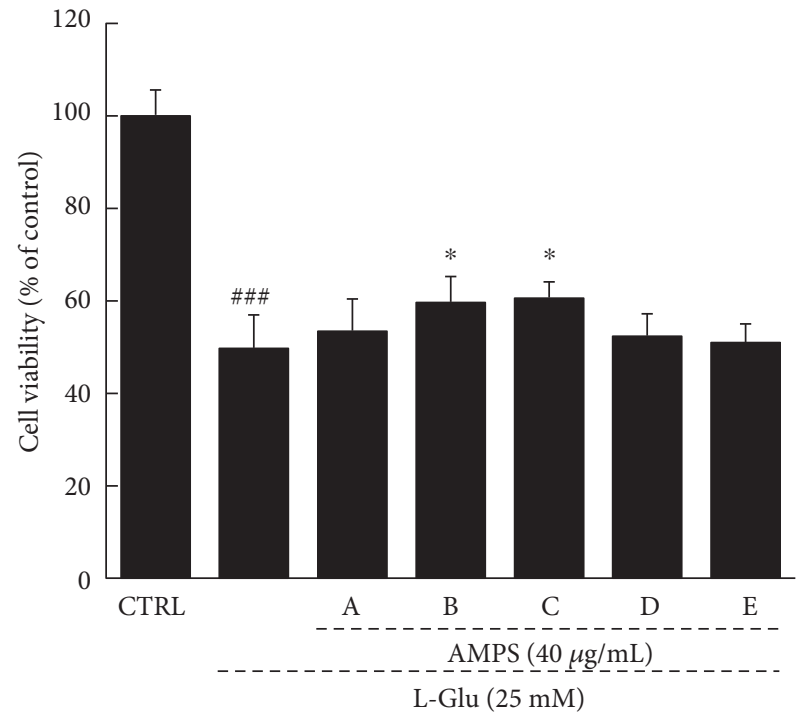

(a)

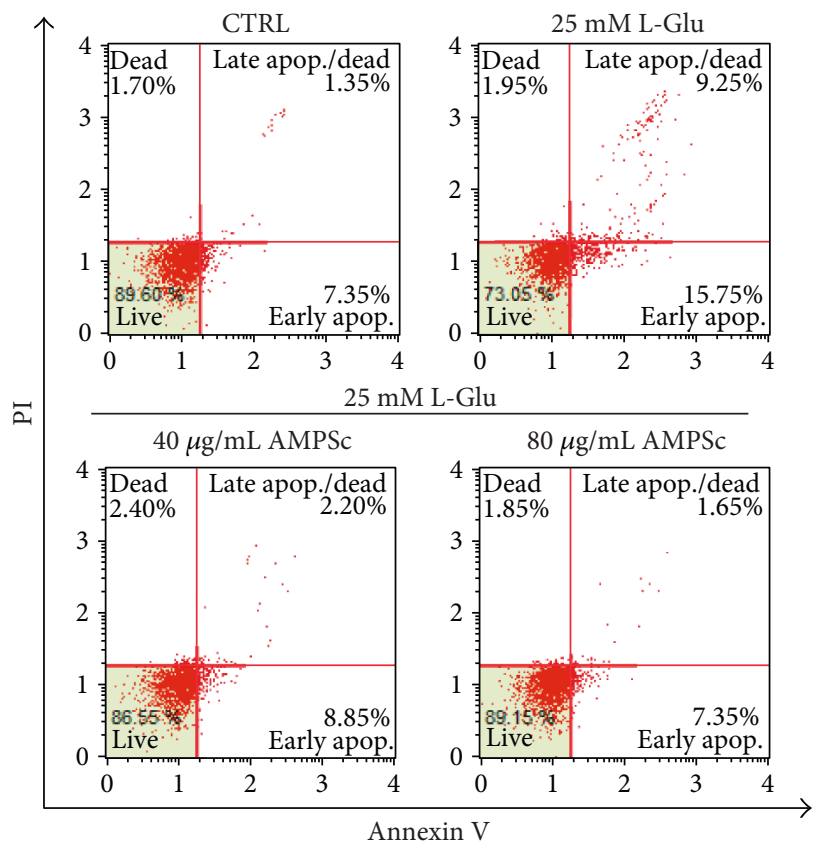

(c)

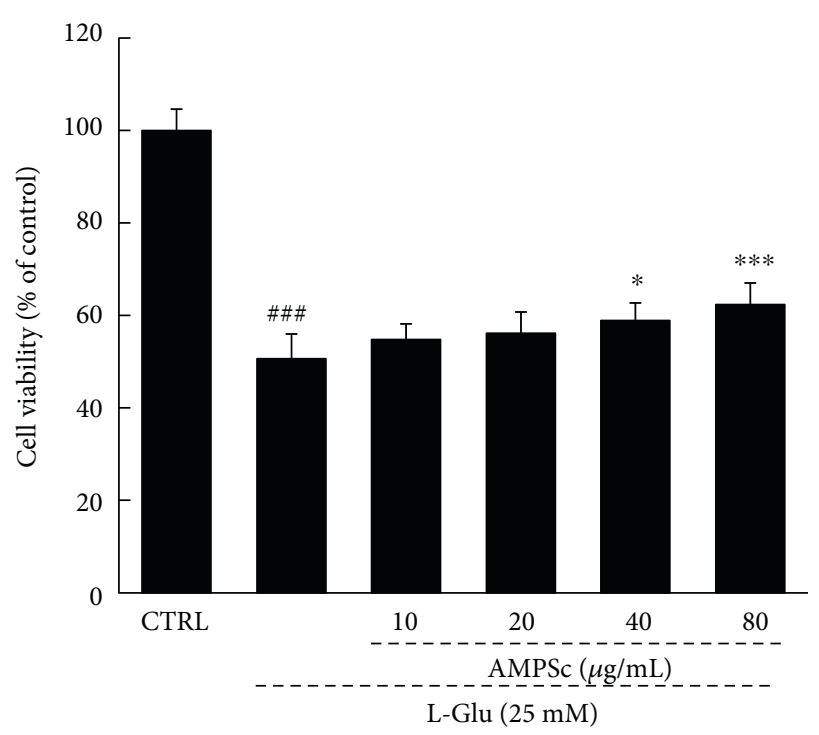

(b)

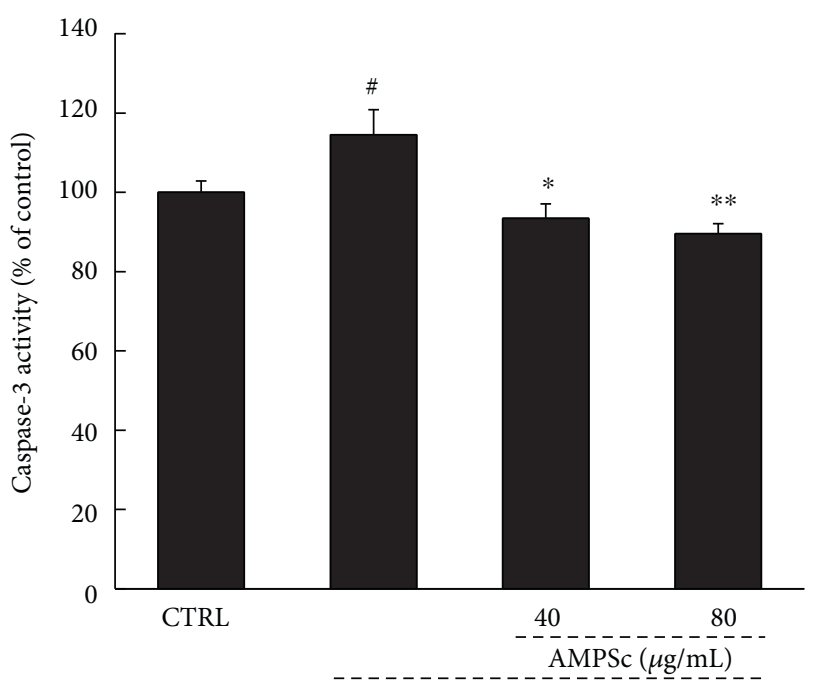

L-Glu (25 mM)

(d)

Figure 2: The neuroprotective effects of AMPS against L-Glu-induced cell damage in HT22 cells. (a) $3 \mathrm{~h}$ AMPSb and c preincubation improved cell viability in L-Glu-exposed HT22 cells. (b) $3 \mathrm{~h}$ AMPSc (40 and $80 \mu \mathrm{g} / \mathrm{mL}$ ) pretreatment improved cell viability in HT22 cells after $24 \mathrm{~h}$ incubation with $25 \mathrm{mM}$ of L-Glu. (c) $3 \mathrm{~h}$ AMPSc preincubation strongly reduced the apoptotic rate of HT22 cells exposed to L-Glu for $24 \mathrm{~h}$. (d) $3 \mathrm{~h}$ AMPSc pretreatment weakened caspase-3 activations in HT22 cells exposed to $25 \mathrm{mM}$ of L-Glu for $24 \mathrm{~h}$. Data were expressed as a percentage of corresponding control cells and means \pm S.E.M. $(n=6)$. ${ }^{\#} P<0.05$ and ${ }^{\# \# \#} P<0.001$ versus CTRL; ${ }^{*} P<0.05,{ }^{* *} P<0.01$, and ${ }^{* * *} P<0.001$ versus L-Glu-exposed cells. AMPS: A. mellea polysaccharides.

A $\beta 1$-42 concentrations $(P<0.05$; Figure 6(a)). Furthermore, AMPSc also increased the serum $A \beta 1-42$ levels in control mice $(P<0.05$; Figure 6(a)). In the hippocampus, AMPSc suppressed the strong expression of $\mathrm{A} \beta$ in $\mathrm{AD}$ mice, as indicated by the reduction in green fluorescence intensity (Figure 6(b)). The suppressive effects of AMPSc on A $\beta 1$ 40 deposition were also confirmed by immunohistochemistry (Figure 6(c)).
3.7. AMPSc Regulated Oxidative Damage and p-Tau Aggregations in Hippocampus. Compared to control mice, high expression levels of 4-NHE (Figure 7, a) and excessive aggregations of $\mathrm{p}$-Tau (Figure $7, \mathrm{~b}$ ) in the hippocampus were noted in $\mathrm{AD}$ mice. In contrast, four-week AMPSc treatment strongly reduced the expression levels of 4-NHE (Figure $7, a$ ) and attenuated the aggregations of $\mathrm{p}$-Tau in $\mathrm{AD}$ mice (Figure 7, b). 


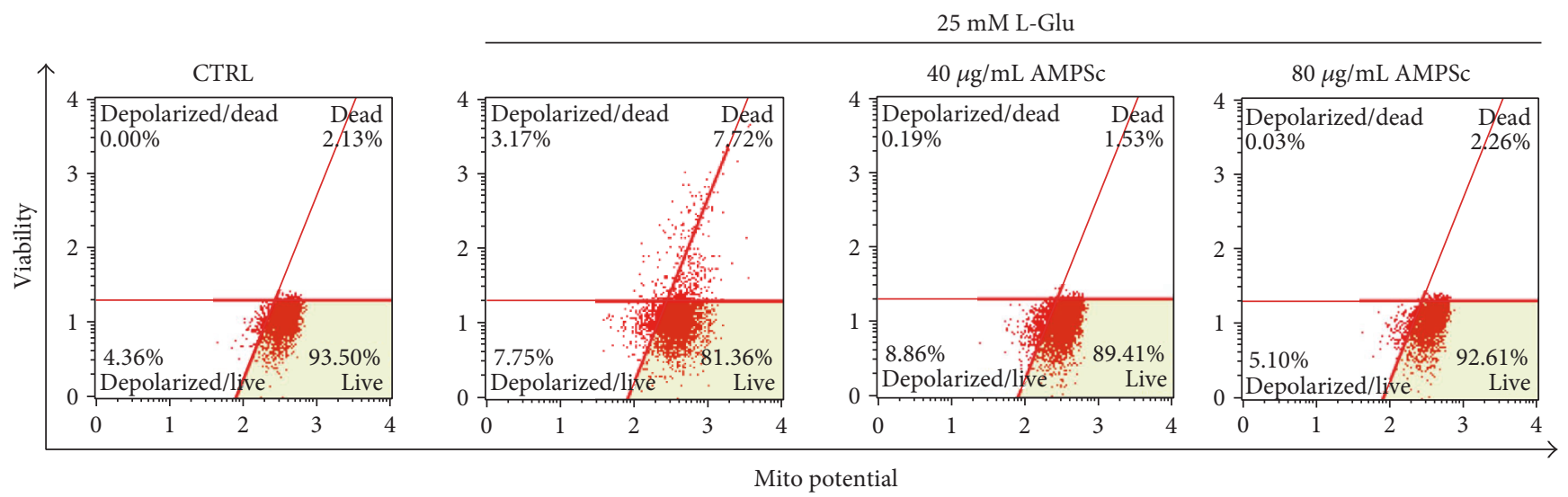

(a)
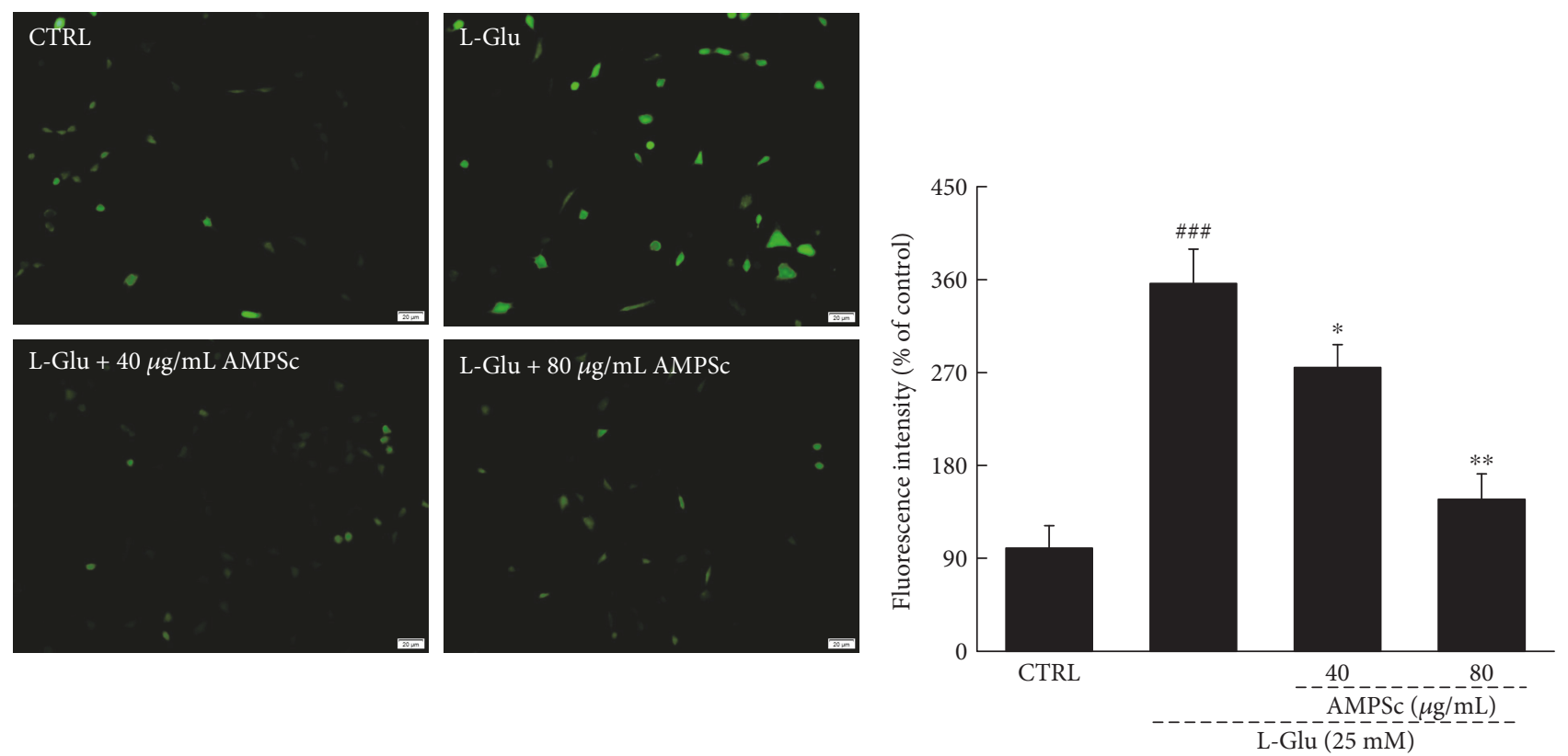

(b)

FIGURE 3: (a) The dissipation of MMP caused by $12 \mathrm{~h} \mathrm{~L}$-Glu incubation was strongly restored by $3 \mathrm{~h}$ AMPSc pretreatment analyzing via JC-1 staining $(n=6)$. (b) The overproduction of ROS induced by $12 \mathrm{~h} \mathrm{L-Glu}$ exposure was significantly decreased by $3 \mathrm{~h}$ AMPSc pretreatment analyzed by DCFH-DA staining $(n=6)$. Scale bar: $20 \mu \mathrm{m}$. Qualification data were expressed as the percentage of green fluorescent intensity compared to control cells. Data are expressed as means \pm S.E.M. $(n=6)$. ${ }^{\# \#} P<0.001$ versus CTRL; ${ }^{*} P<0.05$ and ${ }^{* *} P<0.01$ versus L-Glu-exposed cells. AMPS: A. mellea polysaccharides.

\section{Discussion}

By 2050, the number of patients suffering with dementia is expected to reach 115.4 million [17]. Our present study successfully confirmed the neuroprotective effects of AMPS in L-Glu-induced HT22 apoptotic cells and a chemically induced $\mathrm{AD}$ mouse model, as evidenced by the significant amelioration of nuclear and mitochondrial apoptosis. Furthermore, a clinical decline in short-term memory is considered a symptom of $\mathrm{AD}$, and AMPS was shown to affect the behavior of $\mathrm{AD}$ mice. In contrast to other agents used to treat $\mathrm{AD}$, AMPS contains multiple polysaccharides that affect systemic targets and exert various functions, such as antioxidative and antiapoptotic effects, to eliminate the symptoms of $\mathrm{AD}$ in a much more natural manner.
In our in vitro study, the robust protection provided by AMPS against apoptosis was associated with the inhibition of ROS overproduction and the reversal of MMP depolarization. ROS accumulation causes oxidative stress and thus leads to cellular dysfunction and apoptosis [18], which are associated with the opening of the mitochondrial permeability transition pore [19]. Within a feedback loop, MMP dissipation leads to further ROS release from the mitochondria to the cytoplasm [20], while activating other proapoptotic molecules such as caspase-3 [21]. Caspase-3 is an active component of proteolytic cleavage, which directs the execution of the apoptotic program [22]. Our data obtained from LGlu-induced HT22 apoptotic cells suggest an association between AMPS-mediated neuroprotection and oxidative stress-mediated mitochondrial apoptotic signaling. 


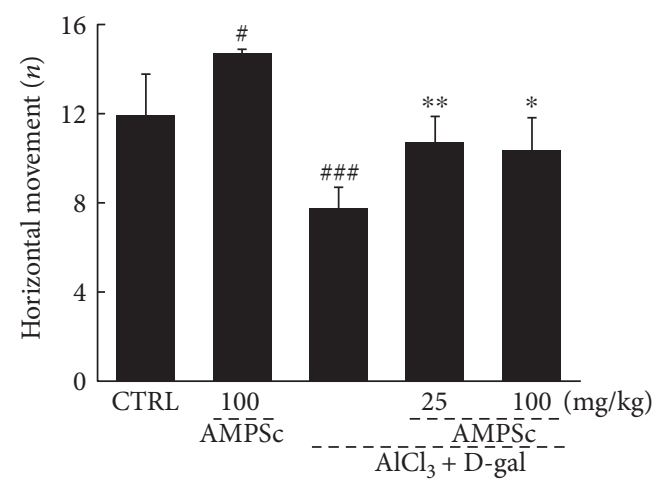

(a)

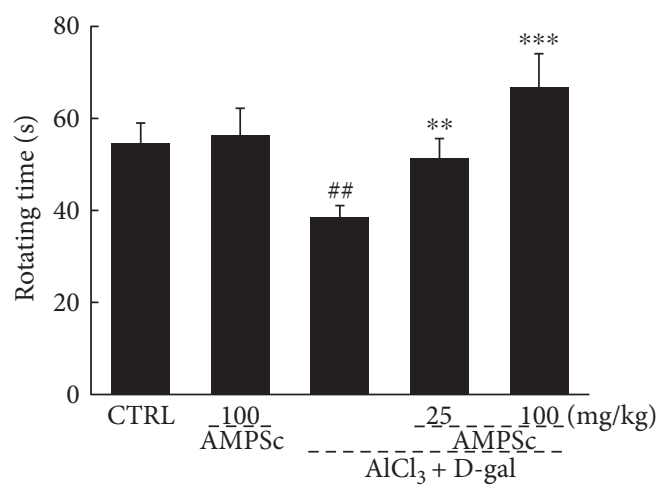

(c)

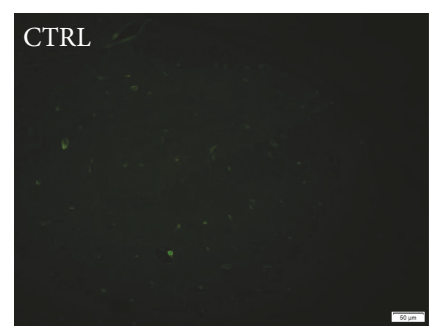

$\mathrm{AlCl}_{3}+\mathrm{D}-\mathrm{gal}+25 \mathrm{mg} / \mathrm{kg}$ AMPSc

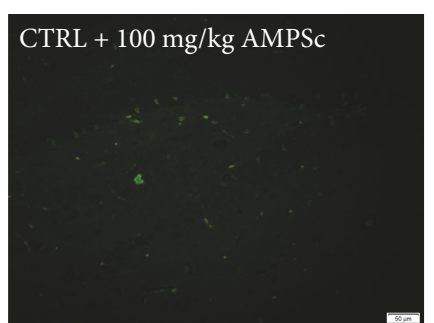

$\mathrm{AlCl}_{3}+\mathrm{D}$-gal $+100 \mathrm{mg} / \mathrm{kg}$ AMPSc

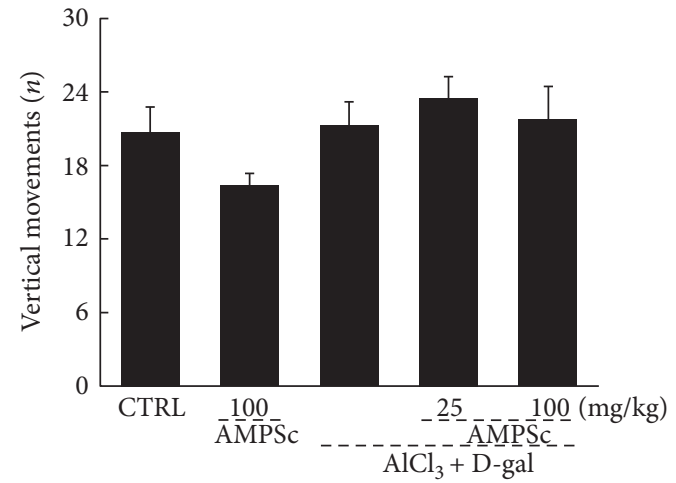

(b)

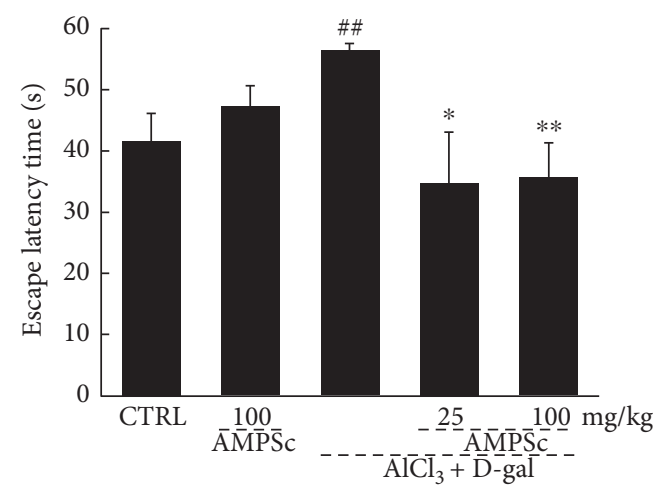

(d)
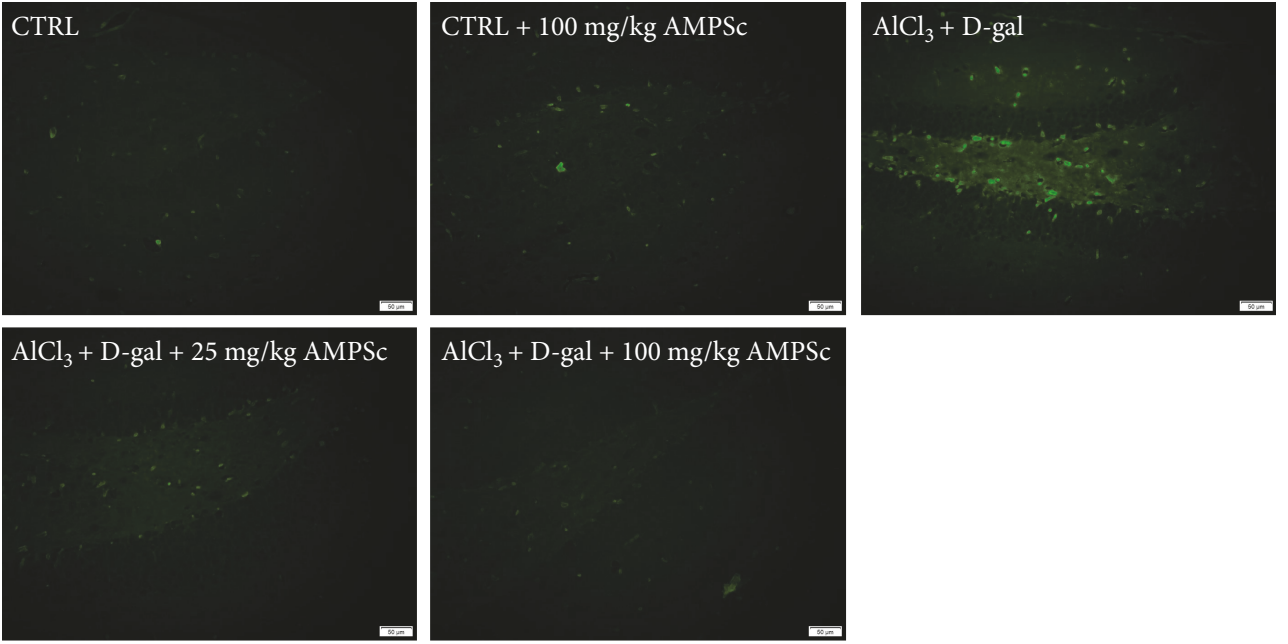

(e)

FIgURE 4: AMPSc improved AD-like behaviors in $\mathrm{AlCl}_{3}$ and D-gal induced $\mathrm{AD}$ mice. AMPSc enhanced (a) horizontal movements, but not (b) vertical movements in autonomous activity test, (c) prolonged endurance time in rotarod test, and (d) decreased escape latency time in water maze test in $\mathrm{AD}$ mice. Data are expressed as mean \pm S.E.M. $(n=10) .{ }^{\#} P<0.05,{ }^{\# \#} P<0.01$, and ${ }^{\# \# \#} P<0.001$ versus normal mice $(\mathrm{CTRL})$; ${ }^{*} P<0.05,{ }^{* *} P<0.01$, and ${ }^{* * *} P<0.001$ versus $\mathrm{AD}$ mice. (e) AMPSc reduced apoptotic cell rate in the hippocampus of AD mice determined by TUNEL assay $(n=6)$. Scale bar: $50 \mu \mathrm{m}$. AMPS: A. mellea polysaccharides.

In the present study, our $\mathrm{AlCl}_{3}$ and $\mathrm{D}$-gal-induced $\mathrm{AD}$ mice exhibited signs of enhanced oxidative stress. As a biomarker of oxidative damage, 4-HNE is a cytotoxic end product of lipid peroxidation, which is essential for cell survival signaling [23]. The increase of 4-HNE triggers inflammatory responses and elevates ROS [24]. Comparatively, AMPS induced significant antioxidative effects, as shown by the suppression on 4-HNE expressions, the reductions in ROS levels, and increases in the activities of the endogenous antioxidants SOD and GSH-Px, which play an important role in removing oxygen-free radicals. $\mathrm{AlCl}_{3}$ has been reported to induce the generation of free radicals and neurotoxicity in the brain, 


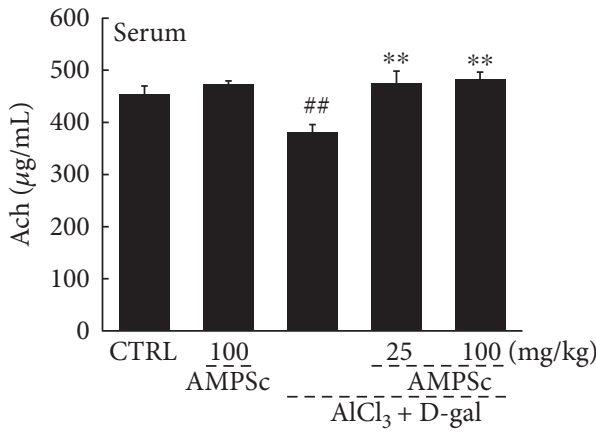

(a)

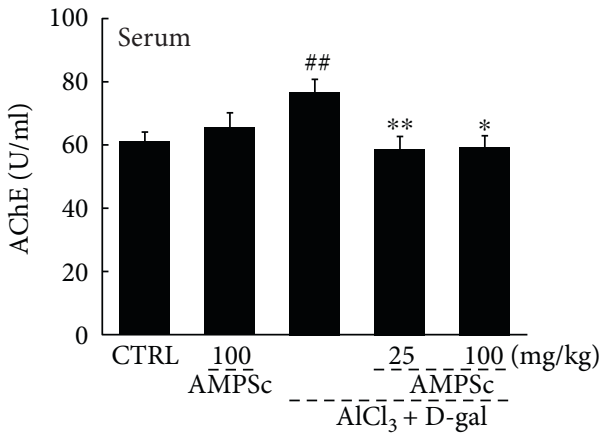

(c)

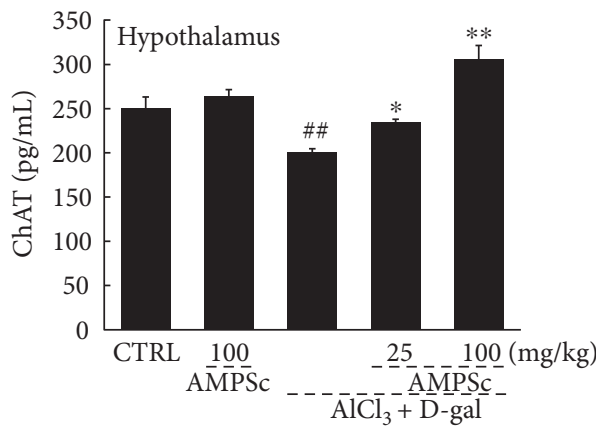

(e)

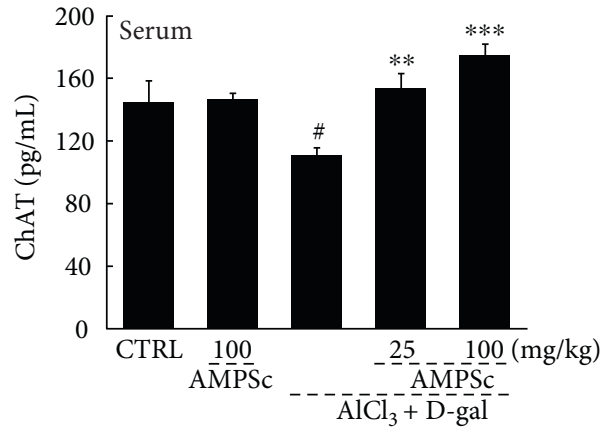

(b)

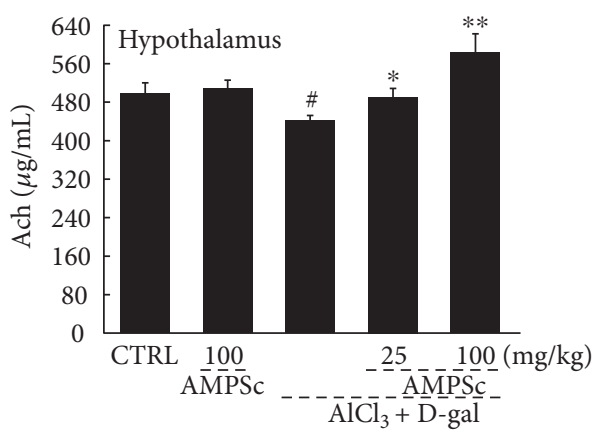

(d)

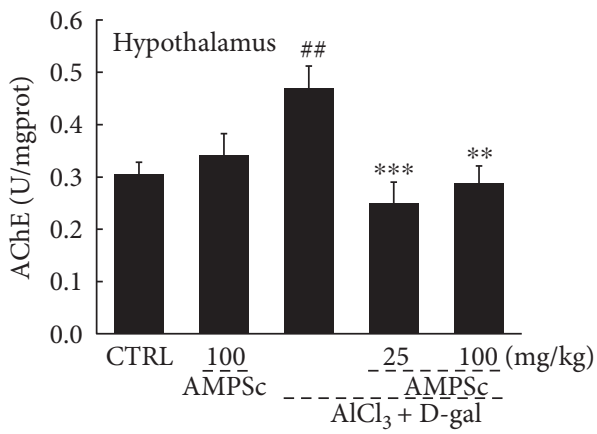

(f)

Figure 5: AMPSc enhanced the levels of ( $a$ and d) Ach and (b and e) ChAT and reduced the levels of (c and f) AchE in serum and hypothalamus of AD mice detecting via ELISA method. Data are expressed as mean \pm S.E.M. $(n=10)$. ${ }^{\#} P<0.05$ and ${ }^{\# \#} P<0.01$ versus normal mice $(\mathrm{CTRL}) ;{ }^{*} P<0.05,{ }^{* *} P<0.01$, and ${ }^{* * *} P<0.001$ versus $\mathrm{AD}$ mice.

TABLE 2: The effects of AMPSc on oxidative statues in serum or hypothalamus in AD mice.

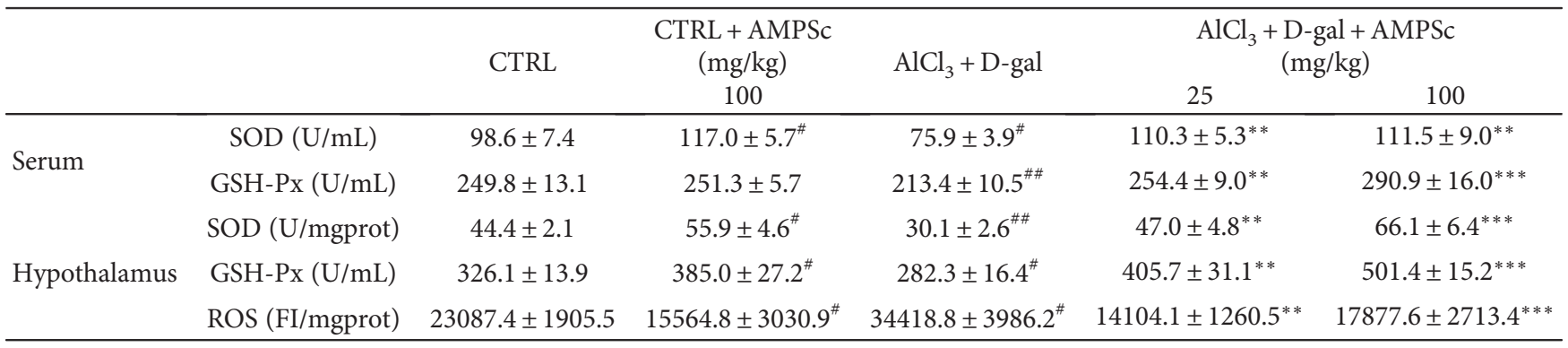

Treatment with AMPSc and the levels of SOD, GSH-Px, and ROS in serum and/or hypothalamus were detected via ELISA method. Data are expressed as mean \pm S.E.M. $(n=10) .{ }^{\#} P<0.05$ and ${ }^{\# \#} P<0.01$ versus normal mice $(\mathrm{CTRL}) ;{ }^{* *} P<0.01$ and ${ }^{* * *} P<0.001$ versus $\mathrm{AD}$ mice. 


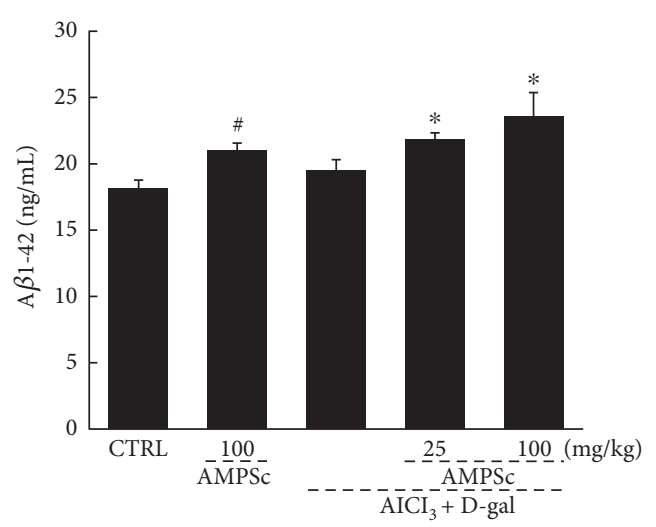

(a)
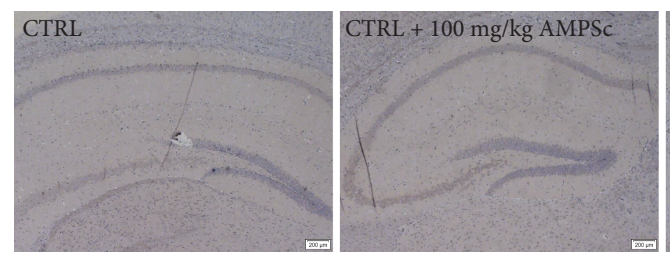
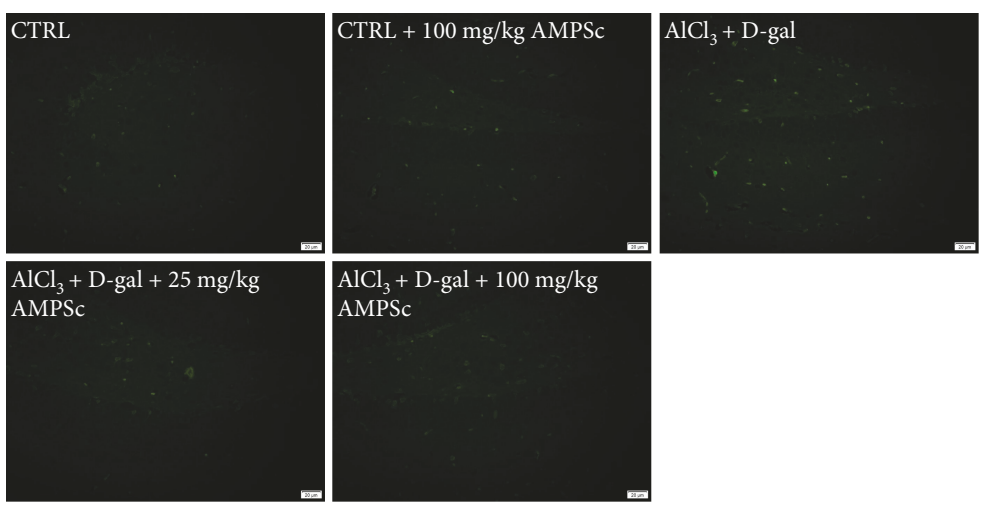

(b)
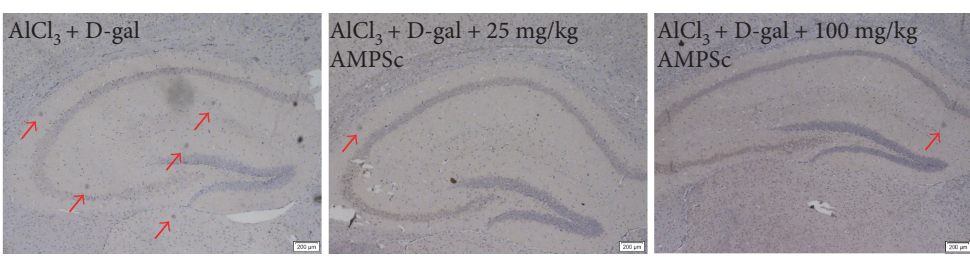

(c)

FIGURE 6: Effect of AMPSc on A $\beta$ clearance in the blood and hippocampus. (a) The levels of $A \beta$ in serum were significantly enhanced by AMPS. Data are expressed as mean \pm S.E.M. $(n=10) .{ }^{*} P<0.05$ versus normal mice (CTRL), ${ }^{*} P<0.05$ versus AD mice. AMPS significantly reduced $\mathrm{A} \beta$ aggregates in hippocampus of $\mathrm{AD}$ mice analyzed via (b) thioflavin-S fluorescence staining $(n=6$; scale bar: $20 \mu \mathrm{m})$ and $(\mathrm{c})$ immunohistochemistry staining $(n=6$; scale bar: $200 \mu \mathrm{m})$. AMPS: A. mellea polysaccharides.

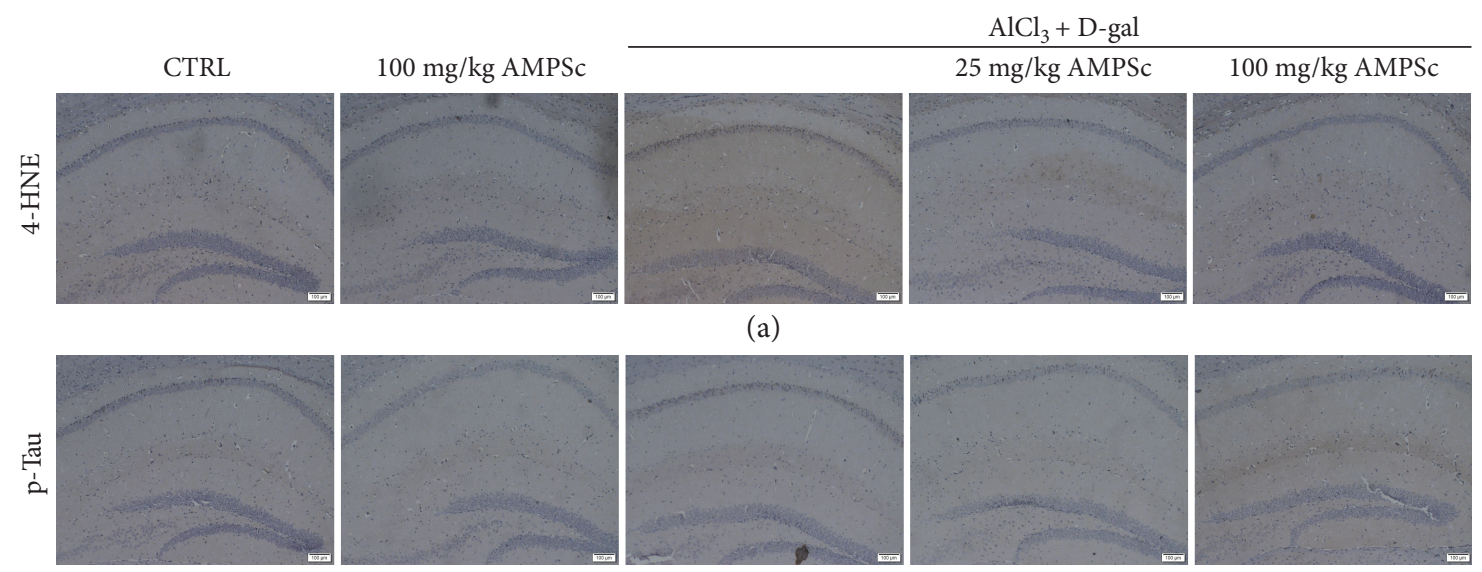

(b)

Figure 7: The effects of AMPSc on (a) 4-HNE expression levels and (b) p-Tau aggregations in hippocampus of AD mouse via immunohistochemistry staining $(n=6)$ (scale bar: $100 \mu \mathrm{m})$. AMPS: A. mellea polysaccharides.

which might lead to degenerative disorders [25]. Over the long term, D-gal injections not only induce impairments in learning and memory but also cause mitochondrial dysfunction and ROS accumulation in the brain [26]. The brain contains large amounts of polyunsaturated fatty acids, and its structure, which can be damaged by oxidation of proteins and lipids, is very sensitive to oxidative stress [27]. In AD, oxidative stress damage causes neuronal cell apoptosis by destroying the balance between ROS generation and mitochondrial removal [28]. D-gal induced the dissipation of MMP, and neurodegeneration is promoted by caspasemediated apoptosis, which mainly occurs in the dentate gyrus (DG) region of the hippocampus [29]. Using TUNEL staining, we confirmed that AMPS successfully suppressed neuronal apoptosis in the hippocampus, compared to nontreated AD mice. Together with our in vitro data, these results demonstrate that the AMPS-induced improvements in the cognitive performances of $\mathrm{AD}$ mice may be related 
to its antioxidant activities, which led to further suppression of apoptosis.

AMPS also enhanced the serum levels of $\mathrm{A} \beta$ while reducing the hippocampal expression of $\mathrm{A} \beta$. The overproduction of $\mathrm{A} \beta$ protein and resulting formation of intracellular neurofibrillary tangles lead to the generation of extracellular senile plaques, which serve as the pathological index in the brain of a rodent with $\mathrm{AD}[30]$. A $\beta$ aggregation induces oxidative stress and mitochondrial dysfunction and leads to the production of ROS, which are involved in the pathogenesis of $\mathrm{AD}$ [31]. In a normal physiological state, $\mathrm{A} \beta$ can be detected in the blood and cerebrospinal fluid as it is slowly removed from the brain into the periphery via the transport mechanism and enzyme degradation. In $\mathrm{AD}$ patients, the clearance of $\mathrm{A} \beta$ accumulated in the brain may cause the increased levels of $\mathrm{A} \beta$ in the peripheral blood [32]. As reported, the fruit of Cornus officinalis, a traditional medicinal agent, exerts neuroprotective activity and significantly increases the plasma levels of $\mathrm{A} \beta$ [33]. On the other hand, the deposits of $\mathrm{A} \beta$ trigger the deficits of memory and synaptic degeneration, which further result in the neuronal signaling downstream of p-Tau pathology. The deposition of tau protein due to abnormal phosphorylation and glycosylation modification eventually leads to the formation of neurofibrillary tangles, which is related to the existence of excessive $\mathrm{A} \beta$ and plaques, proving the tau pathology in AD. We found that the ability of AMPS to reduce the hippocampal deposition of $\mathrm{A} \beta$ in mice played a central role in its ability to improve $\mathrm{AD}$-like behaviors in mice.

The cholinergic system, which involves neurotransmitters such as Ach, is essential for the establishment, storage, and recovery of long-term memory. As reported, the decreases in Ach and ChAT release and enhancement of AchE activity caused by an impaired cholinergic system are key alterations affecting the cognitive deficit characteristic of $\mathrm{AD}$ pathogenesis [34]. Ach, ChAT, and AchE are among the neurotransmitters with crucial roles in synaptic transmission, which is related to memory and learning deficits [35]. $H$. erinaceus extracts were previously found to improve the $\mathrm{AlCl}_{3}$ and D-gal-induced impairment of learning and memory in mice by regulating Ach and ChAT levels [9]. Similarly, the modulatory effects of AMPS on neurotransmitters might define an important protective role of cholinergic function in $\mathrm{AD}$ mice.

Our present study had some limitations. First, although we isolated polysaccharides from A. mellea mycelia, we could not obtain sufficient purity for a structural analysis. Further investigation is required. Second, the relationships among oxidative stress, neurotransmitter levels, and $\mathrm{A} \beta$ deposition should be investigated in greater detail.

In conclusion, our results demonstrate that AMPS protects against L-Glu-induced neurotoxicity in HT22 cells and mitigates $\mathrm{AD}$-like behaviors in an $\mathrm{AlCl}_{3}$ and $\mathrm{D}$-gal-induced mouse model of AD. These effects might be largely attributable to the ability of AMPS to modulate oxidative stress. Our findings provide experimental evidence that A. mellea might be a useful neuroprotective agent for the treatment or prevention of neurodegenerative disease.

\section{Abbreviations}

ANOVA: One-way analysis of variance

Ach: Acetylcholine

AchE: Acetylcholine esterase

AD: $\quad$ Alzheimer's disease

AMPS: A. mellea mycelium polysaccharides

A $\beta$ : $\quad$ Amyloid beta

ChAT: Choline acetyltransferase

DG: Dentate gyrus

D-gal: D-Galactose

ELISA: Enzyme-linked immunosorbent assay

GSH-Px: Glutathione peroxidase

L-Glu: L-Glutamic acid

MMP: $\quad$ Mitochondrial membrane potential

ROS: $\quad$ Reactive oxygen species

SOD: $\quad$ Superoxide dismutase

4-HNE: 4-Hydroxynonenal.

\section{Conflicts of Interest}

The authors have declared that there is no conflict of interest.

\section{Acknowledgments}

This work was supported by the Science and Technology Key Project in Jilin Province of China (Grant nos. 20150203002NY, 20160520036JH, and 20160204029YY).

\section{References}

[1] M. Z. Khan, N. Atlas, and W. Nawaz, "Neuroprotective effects of Caralluma tuberculata on ameliorating cognitive impairment in a d-galactose-induced mouse model," Biomedicine of Pharmacotherapy, vol. 84, pp. 387-394, 2016.

[2] E. Tonnies and E. Trushina, "Oxidative stress, synaptic dysfunction, and Alzheimer's disease," Journal of Alzheimer's Disease, vol. 57, no. 4, pp. 1105-1121, 2017.

[3] M. A. Daulatzai, "Cerebral hypoperfusion and glucose hypometabolism: key pathophysiological modulators promote neurodegeneration, cognitive impairment, and Alzheimer's disease," Journal of Neuroscience Research, vol. 95, no. 4, pp. 943-972, 2017.

[4] K. Pathakoti, L. Goodla, M. Manubolu, and T. Tencomnao, "Metabolic alterations and the protective effect of punicalagin against glutamate-induced oxidative toxicity in HT22 cells," Neurotoxicity Research, vol. 31, no. 4, pp. 521-531, 2017.

[5] J. F. Hu, S. F. Chu, N. Ning et al., "Protective effect of (-)clausenamide against Abeta-induced neurotoxicity in differentiated PC12 cells," Neuroscience Letters, vol. 483, no. 1, pp. 78-82, 2010.

[6] F. U. Amin, S. A. Shah, and M. O. Kim, "Vanillic acid attenuates Abeta1-42-induced oxidative stress and cognitive impairment in mice," Scientific Reports, vol. 7, article 40753, 2017.

[7] L. Janjusevic, M. Karaman, F. Sibul et al., "The lignicolous fungus Trametes versicolor (L.) Lloyd (1920): a promising natural source of antiradical and AChE inhibitory agents," Journal of Enzyme Inhibition and Medicinal Chemistry, vol. 32, no. 1, pp. 355-362, 2017.

[8] S. Hu, D. Wang, J. Zhang et al., "Mitochondria related pathway is essential for polysaccharides purified from Sparassis crispa 
mediated neuro-protection against glutamate-induced toxicity in differentiated PC12 cells," International Journal of Molecular Sciences, vol. 17, no. 2, 2016.

[9] J. Zhang, S. An, W. Hu et al., "The neuroprotective properties of Hericium erinaceus in glutamate-damaged differentiated PC12 cells and an Alzheimer's disease mouse model," International Journal of Molecular Sciences, vol. 17, no. 11, 2016.

[10] K. C. Siu, L. Xu, X. Chen, and J. Y. Wu, "Molecular properties and antioxidant activities of polysaccharides isolated from alkaline extract of wild Armillaria ostoyae mushrooms," Carbohydrate Polymers, vol. 137, pp. 739-746, 2016.

[11] J. Wu, J. Zhou, Y. Lang et al., “A polysaccharide from Armillaria mellea exhibits strong in vitro anticancer activity via apoptosis-involved mechanisms," International Journal of Biological Macromolecules, vol. 51, no. 4, pp. 663-667, 2012.

[12] T. Liu, M. Lee, J. J. Ban, W. Im, I. Mook-Jung, and M. Kim, "Cytosolic extract of human adipose stem cells reverses the amyloid beta-induced mitochondrial apoptosis via P53/ Foxo3a pathway," PLoS One, vol. 12, no. 1, article e0168859, 2017.

[13] H. Chu, A. Zhang, Y. Han et al., "Metabolomics approach to explore the effects of Kai-Xin-San on Alzheimer's disease using UPLC/ESI-Q-TOF mass spectrometry," Journal of Chromatography B, Analytical Technologies in the Biomedical and Life Sciences, vol. 1015-1016, pp. 50-61, 2016.

[14] Y. Luo, F. Niu, Z. Sun et al., "Altered expression of A $\beta$ metabolism-associated molecules from d-galactose/AlCl3 induced mouse brain," Mechanisms of Ageing and Development, vol. 130, no. 4, pp. 248-252, 2009.

[15] M. He, J. Liu, S. Cheng, Y. Xing, and W. Z. Suo, "Differentiation renders susceptibility to excitotoxicity in HT22 neurons," Neural Regeneration Research, vol. 8, no. 14, pp. 1297-1306, 2013.

[16] S. Athari Nik Azm, M. Vafa, M. Sharifzadeh, M. Safa, A. Barati, and A. Mirshafiey, "Effects of M2000 (D-mannuronic acid) on learning, memory retrieval, and associated determinants in a rat model of Alzheimer's disease," American Journal of Alzheimer's Disease and Other Dementias, vol. 32, no. 1, pp. 12-21, 2017.

[17] P. H. Reddy, S. Tonk, S. Kumar et al., “A critical evaluation of neuroprotective and neurodegenerative microRNAs in Alzheimer's disease," Biochemical and Biophysical Research Communications, vol. 483, no. 4, pp. 1156-1165, 2017.

[18] D. I. Brown and K. K. Griendling, "Regulation of signal transduction by reactive oxygen species in the cardiovascular system," Circulation Research, vol. 116, no. 3, pp. 531-549, 2015.

[19] M. L. Circu and T. Y. Aw, "Reactive oxygen species, cellular redox systems, and apoptosis," Free Radical Biology \& Medicine, vol. 48, no. 6, pp. 749-762, 2010.

[20] X.-Q. Tang, J.-Q. Feng, J. Chen et al., "Protection of oxidative preconditioning against apoptosis induced by $\mathrm{H} 2 \mathrm{O} 2$ in $\mathrm{PC} 12$ cells: mechanisms via MMP, ROS, and Bcl-2," Brain Research, vol. 1057, no. 1-2, pp. 57-64, 2005.

[21] F. Bensassi, C. Gallerne, O. S. el Dein, M. R. Hajlaoui, H. Bacha, and C. Lemaire, "Mechanism of Alternariol monomethyl ether-induced mitochondrial apoptosis in human colon carcinoma cells," Toxicology, vol. 290, no. 2-3, pp. 230240, 2011.

[22] D. Hippe, A. Gais, U. Gross, and C. G. Luder, "Modulation of caspase activation by Toxoplasma gondii," Methods in Molecular Biology, vol. 470, pp. 275-288, 2009.
[23] A. Fragoulis, S. Siegl, M. Fendt et al., "Oral administration of methysticin improves cognitive deficits in a mouse model of Alzheimer's disease," Redox Biology, vol. 12, pp. 843-853, 2017.

[24] P. Cisternas, C. B. Lindsay, P. Salazar et al., "The increased potassium intake improves cognitive performance and attenuates histopathological markers in a model of Alzheimer's disease," Biochimica et Biophysica Acta (BBA) - Molecular Basis of Disease, vol. 1852, no. 12, pp. 2630-2644, 2015.

[25] A. Justin Thenmozhi, M. Dhivyabharathi, T. Manivasagam, and M. M. Essa, "Tannoid principles of Emblica officinalis attenuated aluminum chloride induced apoptosis by suppressing oxidative stress and tau pathology via Akt/GSK-3 $\beta$ signaling pathway," Journal of Ethnopharmacology, vol. 194, pp. 20-29, 2016.

[26] Z. Qu, J. Zhang, H. Yang et al., "Protective effect of tetrahydropalmatine against d-galactose induced memory impairment in rat," Physiology \& Behavior, vol. 154, pp. 114-125, 2016.

[27] T. Jiang, Q. Sun, and S. Chen, “Oxidative stress: a major pathogenesis and potential therapeutic target of antioxidative agents in Parkinson's disease and Alzheimer's disease," Progress in Neurobiology, vol. 147, pp. 1-19, 2016.

[28] M. Paul, R. M. Thushara, S. Jagadish et al., "Novel sila-amide derivatives of $\mathrm{N}$-acetylcysteine protects platelets from oxidative stress-induced apoptosis," Journal of Thrombosis and Thrombolysis, vol. 43, no. 2, pp. 209-216, 2017.

[29] S. U. Rehman, S. A. Shah, T. Ali, J. I. Chung, and M. O. Kim, "Anthocyanins reversed D-galactose-induced oxidative stress and neuroinflammation mediated cognitive impairment in adult rats," Molecular Neurobiology, vol. 54, no. 1, pp. 255271, 2017.

[30] X. Y. Song, Y. Y. Wang, S. F. Chu et al., "A new coumarin derivative, IMM-H004, attenuates okadaic acid-induced spatial memory impairment in rats," Acta Pharmacologica Sinica, vol. 37, no. 4, pp. 444-452, 2016.

[31] D. I. Kim, K. H. Lee, A. A. Gabr et al., "Abeta-induced Drp1 phosphorylation through Akt activation promotes excessive mitochondrial fission leading to neuronal apoptosis," Biochimica et Biophysica Acta (BBA) - Molecular Cell Research, vol. 1863, no. 11, pp. 2820-2834, 2016.

[32] M. Fei, W. Jianghua, M. Rujuan, Z. Wei, and W. Qian, "The relationship of plasma Abeta levels to dementia in aging individuals with mild cognitive impairment," Journal of the Neurological Sciences, vol. 305, no. 1-2, pp. 92-96, 2011.

[33] J. W. Lee, "Fructus corni officinalis water extract ameliorates memory impairment and beta amyloid $(\mathrm{A} \beta)$ clearance by LRP-1 expression in the hippocampus of a rat model of Alzheimer's disease," Journal of Physiology \& Pathology in Korean Medicine, vol. 30, no. 5, p. 347, 2016.

[34] G. A. Elmegeed, H. H. Ahmed, M. A. Hashash, M. M. AbdElhalim, and D. S. El-kady, "Synthesis of novel steroidal curcumin derivatives as anti-Alzheimer's disease candidates: evidences-based on in vivo study," Steroids, vol. 101, pp. 7889, 2015.

[35] K. Biswas, A. K. Azad, T. Sultana et al., "Assessment of in-vitro cholinesterase inhibitory and thrombolytic potential of bark and seed extracts of Tamarindus indica (L.) relevant to the treatment of Alzheimer's disease and clotting disorders," Journal of Intercultural Ethnopharmacology, vol. 6, no. 1, pp. 115-120, 2017. 


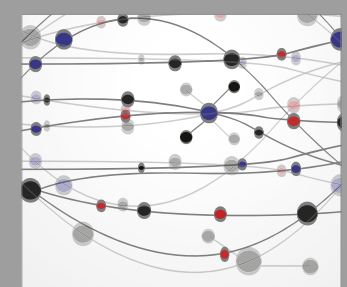

The Scientific World Journal
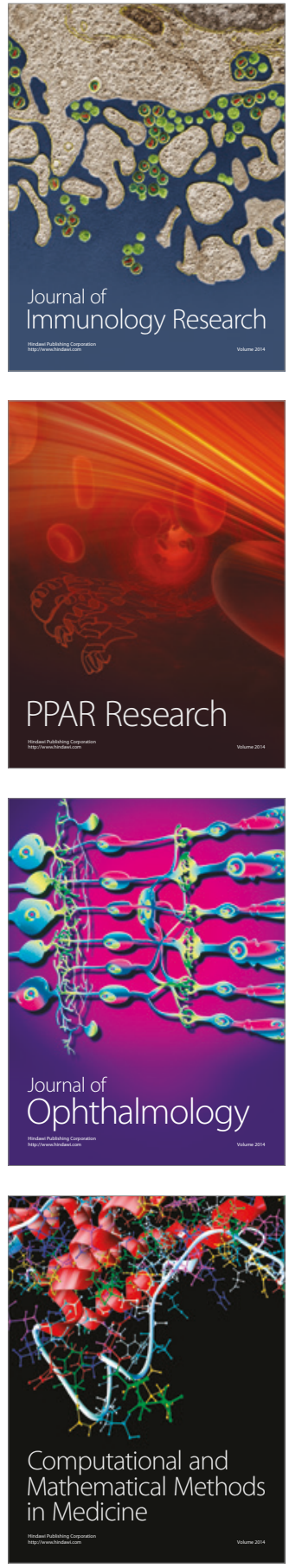

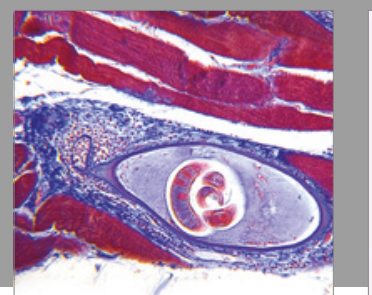

Gastroenterology Research and Practice
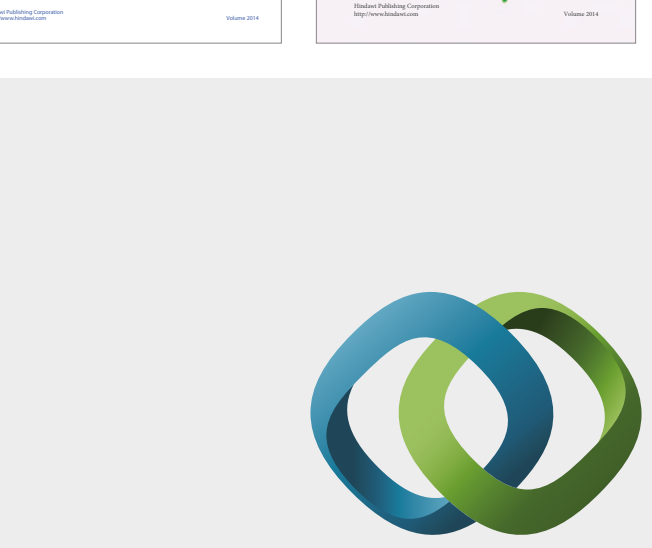

\section{Hindawi}

Submit your manuscripts at

https://www.hindawi.com
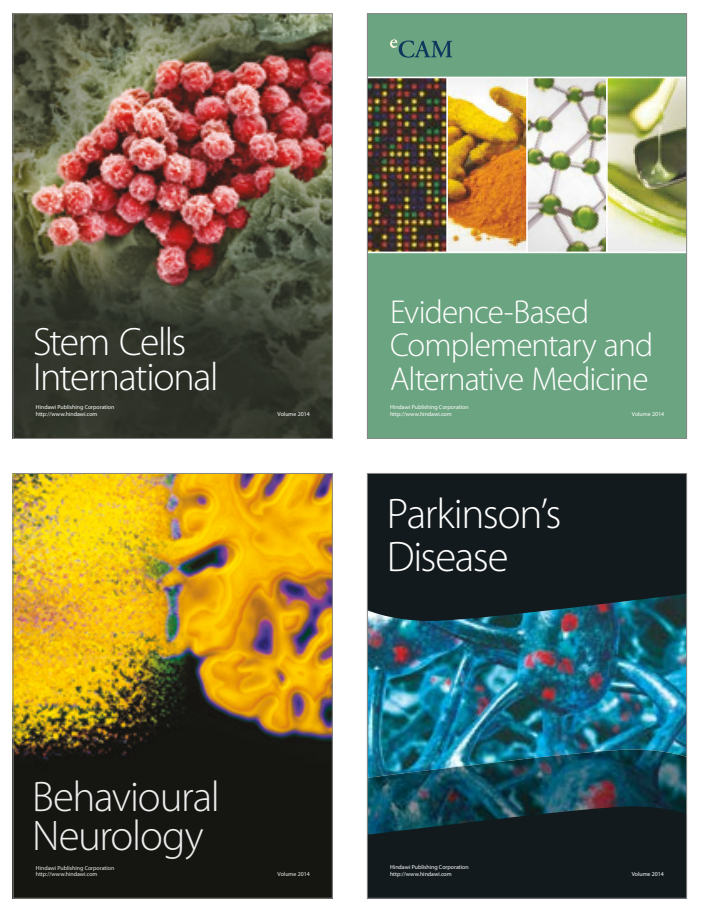
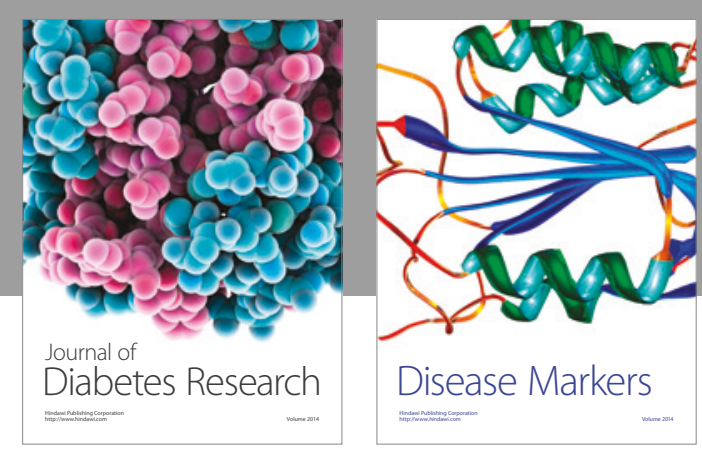

Disease Markers
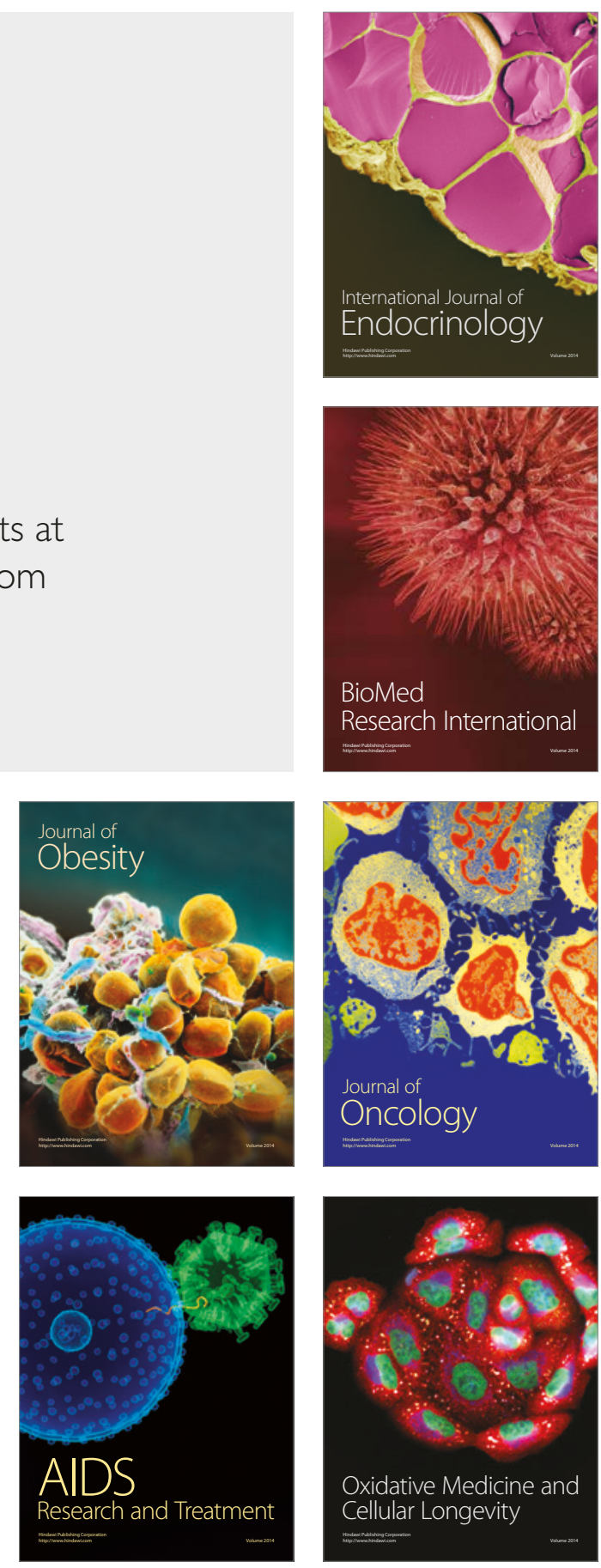